\title{
REVISTA MANDRÁGORA: GÊNERO E RELIGIÃO NOS ESTUDOS FEMINISTAS
}

\author{
SANDRA DUARTE DE SOUZA \\ Universidade Metodista de São Paulo - UMESP
}

\begin{abstract}
Resumo: Gênero e religião compõem uma equação ainda pouco discutida e pouco admitida. No campo dos Estudos Feministas essa relação ainda é abordada de forma muito acanhada. As iniciativas de estudo dessa temática são bastante escassas, especialmente no que tange à publicação de periódicos específicos a esse respeito. Duas das revistas acadêmicas feministas mais expressivas do Brasil - Revista Estudos Feministas e Cadernos Pagu - têm sido um espaço importante de discussão dessa temática. Uma outra publicação que se destaca nessa área é a Mandrágora, uma revista específica sobre Estudos Feministas e Religiáo, sobre a qual nos deteremos um pouco mais.
\end{abstract}

Palavras-chove: gênero, religião, publicações feministas

No Brasil, a religião enquanto objeto de estudo sistemático ocupou "um lugar marginal e de importância secundária" na academia. ' Tal resistência, que em certa dose ainda persiste, provavelmente derive da herança que nos legou o positivismo e sua aversão quase religioso-fundamentalista ao tema. ${ }^{2}$ Todavia, essa aparente impermeabilidade acadêmica é cada vez mais permeável a essa discussão.Conforme apontam Beatriz Muniz de Souza e Luís Mauro Sá Martino, ${ }^{3}$ não obstante os trabalhos de estudiosos como Émile Durkheim, Max Weber e Karl Marx, os estudos sobre religião no país começam a superar os limites da mera história eclesiástica somente a partir da década de 70 , quando uma certa organicidade entre estudiosos da religião e instituições religiosas começa a ceder lugar a uma nova maneira de compreender o fenômeno. O livro de Cândido Procópio Ferreira Camargo, Católicos, Protestantes, Espíritas, ${ }^{4}$ é um marco importante dessa mudança de perspectiva. Com o intuito de analisar a relação entre religião e mudança social, Camargo inaugura uma nova fase da pesquisa brasileira nessa área. É importante destacar também as pesquisas de Roger Bastide que contribuíram "para que o meio universitário brasileiro viesse a reconhecer a relevância da religião como significativo objeto de análise sociológica". ${ }^{5}$ Em suma, nas últimas décadas o interesse científico pela religião tem sido crescente como bem têm evidenciado os estudiosos do fenômeno.

Analisar o fenômeno religioso não é tarefa simples, implicando entende-lo como uma realidade situada, limitada e orientada socialmente, influenciando e sendo influenciada pelo meio que a gestou. Não é sem razão que a religião ocupa um importante lugar nos estudos socio-antropológicos, pois na pergunta pela dinâmica social cabe a pergunta pelos 'dinamizadores sociais'.

A religião é, antes de tudo, uma construção sócio-cultural. Portanto, discutir religião é discutir transformações sociais, relações de poder, de classe, de gênero, de raça/etnia; 
é adentrar num complexo sistema de trocas simbólicas, de jogos de interesse, na dinâmica da oferta e da procura; é deparar-se com um sistema sócio-cultural permanentemente redesenhado que permanentemente redesenha as sociedades.

Esse fenômeno nada estático, mesmo quando cristalizado nas organizações religiosas, demanda um olhar mais atento dos estudos feministas. Os sistemas simbólicos religiosos $^{6}$ se constituem em importantes mecanismos de construção da subjetividade humana, atuando de maneira estruturada e estruturante. Apesar da perda do poder regulador da religião nas sociedades secularizadas ${ }^{7}$ o que se verifica é ainda um forte religious appeal na maneira como os sexos se reconhecem socialmente.

Se, por um lado, na atualidade, existe um certo consenso nas Ciências Sociais acerca da importância do fenômeno religioso como dinamizador da sociedade, por outro, parece que os estudos feministas no Brasil ainda não estão completamente à vontade na discussão dessa temática. Gênero e religião compõem uma equação ainda pouco discutida e pouco admitida, abordada de forma muito acanhada. As iniciativas de estudo dessa temática são ainda bastante escassas, especialmente no que tange à publicação de periódicos específicos a esse respeito. Duas das revistas acadêmicas feministas mais expressivas do Brasil - Revista Estudos Feministas e Cadernos Pagu - têm sido um espaço importante de discussão dessa temática. Vários são os artigos que articulam gênero e religião, apesar de representarem menos de $10 \%$ do total de artigos publicados desde a criação de ambas as revistas. Uma outra publicação que se destaca nessa área é a Mandrágora, uma revista cujo objetivo é proceder à discussão do fenômeno religioso numa perspectiva feminista. O número reduzido de publicações a esse respeito é um indicador importante da pouca atenção que temos dedicado à religião como um mecanismo ainda eficaz de construção e redefinição das identidades de gênero, ${ }^{8}$ mesmo no contexto de uma sociedade secularizada. Com isso queremos afirmar que os estudos feministas encontram na religião um campo fértil e ainda pouco explorado na discussão de gênero. Num país declaradamente religioso como o Brasil, mesmo que o poder religioso esteja relativizado pelas implicações da secularização, pensar as representações de gênero demanda pensar o papel da religião na construção social dos sexos.

\section{A "religião publicada" nos Estudos Feministas}

Um levantamento dos textos publicados nos Cadernos Pagu, revista produzida pelo Núcleo de Estudos de Gênero "Pagu", da UNICAMP, e pela Revista Estudos Feministas, originalmente uma publicação da Universidade Federal do Rio de Janeiro e, desde 1999, da Universidade Federal de Santa Catarina, revela que existe um significativo interesse pela discussão da complexa temática da religião. Escritos em perspectiva histórica envolvendo mulheres e instituições eclesiásticas em intrincados jogos de poder; escritos em perspectiva antropológica, revelando através de trabalho etnográfico, as não tão simples construções de gênero no universo cultural-religioso indígena; escritos em perspectiva sociológica que desvelam universos pouco explorados pelos Estudos Feministas, como o campo religioso protestante e pentecostal e sua forte influência sobre a construção social dos sexos, registram a validade e importância do tema com o qual estamos dialogando. A abordagem a partir de diferentes olhares disciplinares que caracteriza os Cadernos Pagu se reflete no balanço das publicações específicas sobre gênero e religião e desafiam os Estudos Feministas a colocarem-se na vanguarda dessa discussão.

Os textos da Revista Estudos Feministas que cruzam religião e gênero seguem vários caminhos: tentativas de diálogo com a teologia feminista e a teologia ecofeminista (numa perspectiva analítica), assuntos relativos à moral sexual religiosa (católica e protestante), 
abordagens das implicações de gênero nas formas religiosas afro-brasileiras e abordagens das implicações de gênero nas formas culturais-religiosas indígenas. Assim como os Cadernos Pagu, também a REF tem sido uma importante referência para os trabalhos desenvolvidos no contexto dos estudos de religião e gênero. É interessante notar que o primeiro artigo da primeira revista lançada (1992) foi justamente escrito por uma socióloga da religião, acerca da teologia feminista.

A presença significativa, mas ainda tímida de textos que discutam a relação gênero e religião nas mais diversas publicações feministas parece refletir a herança moderna do feminismo. A tensão entre a razão moderna e tudo o que de primitivo e medieval poderia conter a religião, parece pairar também sobre o dossel sagrado do feminismo e dificultar a incorporação da discussão sobre o fenômeno religioso no contexto dos estudos de gênero, negando assim a possibilidade do debate acerca da influência da religião sobre a construção social dos sexos.

A esse respeito, vale dizer que quando nossos escritos referem-se a comunidades indígenas, a discussão do universo simbólico religioso é como que obrigatória para o entendimento das relações sociais de sexo. Todavia, parece que essa necessidade desaparece quando se trata de analisar outros grupos sociais não indígenas. Não quero com isso simplificar a questão. Como já apontei:

\begin{abstract}
É verdade que, numa sociedade como a nossa em que existem mecanismos plurais de construção da subjetividade humana, presenciamos uma relativização do poder significante da religião. Porém, se o processo de secularização tem contribuído para a "periferização" da religião em relação ao "núcleo forte" da sociedade, isto é, se a religião já não ocupa mais o lugar de matriz cultural totalizante," deixando de ser o centro organizador das relações sociais, ela ainda exerce influência significativa no cotidiano das pessoas. Se, por um lado, experimentamos a crise das instituições tradicionais produtoras de sentido, por outro verificamos o esforço de "recuperação das tradições perdidas" por parte de indivíduos, grupos e principalmente das instituições religiosas. Não se trata, portanto, de um processo linear que, paulatina e progressivamente excluirá a religião do campo das instituições produtoras de sentido [e, por conseguinte, não teria que ser estudado]. Se essa influência não fosse significativa, por que toda a movimentação feminista em favor da laicização do Estado? O que dizer das recorrentes decisões cotidianas tomadas sob a pressão da confissão religiosa como, por exemplo, manter um casamento cuja história mais freqüente é a da violência doméstica? É possível simplesmente fechar os olhos à ingerência religiosa sobre a sexualidade humana? ${ }^{10}$
\end{abstract}

A Revista Mandrágora surgiu provocada justamente por essas questões. A transversalidade do gênero obriga-nos à discussão do objeto religioso. "As pesquisas baseadas no eixo gênero e religião se justificam pelo simples fato de que existe aí uma intimidade pouco verbalizada, mas experimentada, vivenciada no habitus social, "' que é estruturado e que estrutura a vida em sociedade". ${ }^{12}$ Revelar essa intimidade é revelar também a cumplicidade da religião sobre o processo de socialização de homens e mulheres, e de reprodução das assimetrias sociais.

A religião, ainda hoje, exerce uma importante função de produção e reprodução de sistemas simbólicos que têm influência direta sobre as relações sociais de sexo. As representações sociais acerca do homem e da mulher, portanto, não podem ser entendidas sem lançarmos o olhar sobre ela e sobre suas implicações na construção social desse homem e dessa mulher.

Se a religião não mais aparece como constituidora solitária das identidades, principalmente num contexto de identidades múltiplas e frágeis, ela ainda tem um papel importante nesse processo. A Revista Mandrágora cruza gênero e religião, num esforço 
de discutir sua cumplicidade e, muitas vezes, seu protagonismo no processo de construção das identidades de gênero e sua hierarquização.

\section{Mandrágora: raiz de sabedoria ${ }^{13}$}

Em 1994, um grupo de alunas da Pós-Graduação em Ciências da Religião do então Instituto Metodista de Ensino Superior - IMS, ${ }^{14}$ publicou o primeiro número da Revista Mandrágora. Participantes ativas do Núcleo de Estudos Teológicos da Mulher na América Latina - NETMAL, ${ }^{15}$ essas mulheres decidiram iniciar uma publicação que permitisse o entrecruzamento de gênero e religião. Mandrágora conta com a colaboração de pesquisadoras e pesquisadores da UMESP e de outras universidades, do Brasil e de outros países. São teólogas/os, biblistas e cientistas sociais que se revezam na produção de textos direcionados tanto para a academia quanto para o movimento de mulheres. Os objetivos da revista se confundem com os do próprio Núcleo, ${ }^{16}$ buscando-se "motivar o uso de gênero como categoria analítica"; "promover o envolvimento de pesquisadoras e pesquisadores das diversas áreas de conhecimento com temas feministas"; "estimular a análise a partir do uso integrado das categorias de gênero, classe e etnia"; e "estimular a produção científica por parte dos membros do Núcleo".

A revista é anual, quase auto-sustentável, tem uma tiragem de 700 exemplares e tem abordado temas de ponta como "religião, direitos reprodutivos e aborto"; "estudos feministas e cristianismo"; "gênero, cultura e religião"; "direitos reprodutivos, religião e ética"; "religião e homossexualidade"; "ecofeminismo: tendências e debates"; "história, gênero e religião"; "violência, gênero e religião".

Desde o seu início a Mandrágora tem sintetizado o esforço do NETMAL de compreender a complexa relação entre gênero e religião. Talvez nem sempre as abordagens contemplem gênero e religião. Algumas vezes faz-se um pouco de história das mulheres, recuperando personagens históricos ocultados pela chamada história oficial: um pouco de teologia feminista, provocando anomia na ortodoxia estabelecida pelo nomos religioso; e um pouco de poesia, sexualizando e erotizando a relação com o sagrado...

O primeiro número da revista tomou a temática do aborto e direitos reprodutivos visando analisá-la sob o olhar da ética feminista e da hermenêutica bíblica feminista. Como a maioria das participantes do núcleo tem algum tipo de militância, uma parte da revista registrou um pouco de nossas experiências junto aos grupos com os quais trabalhávamos naquele momento, e como a questão dos direitos reprodutivos era tratada.

O número 2 colocou em diálogo os estudos feministas e o cristianismo. Dessa vez o olhar pairava sobre a necessidade de desvelar as relações de poder que tecem a lógica das instituições religiosas cristãs. Isso foi feito a partir da discussão da cristologia feminista, do problema da ordenação religiosa de mulheres, passando pela discussão da ética teológica feminista.

O desafio de articular gênero, cultura e religião foi o que motivou a produção da Mandrágora 3. A partir da noção de cultura como sistema simbólico, buscou-se discutir como se dão as relações de gênero nas diversas expressões culturais-religiosas. Perguntouse pelas construções sociais de sexo no cristianismo, nas religiões afro-brasileiras, nas religiões indígenas... Desafiou-se o público leitor a estabelecer novas hermenêuticas.

Direitos reprodutivos, religião e ética é o tema da Mandrágora 4. Retomamos o tema dos direitos reprodutivos iniciado na Mandrágora 1 . Aqui, porém, nosso enfoque se deu sobre direitos reprodutivos e cidadania, sobre a ingerência da lgreja (no caso, a católica) sobre o exercício da sexualidade, lembrando que muitas vezes as práticas 
reprodutivas das mulheres contrariam os discursos normativos da igreja. Também tratouse da tensão entre desejo e culpa, experimentada por mulheres religiosas, bem como buscou-se destacar a necessidade de entender as mulheres como sujeito ético principal na discussão dos direitos reprodutivos.

Apesar de ser uma publicação incômoda no contexto de uma universidade confessional, a primeira tentativa de censura da Revista Mandrágora foi com o número 5, que é um número referente a "religião e homossexualidade". Nesse número, buscamos, nas palavras de Maria José Rosado Nunes, "desconstruir o entulho ideológico-religioso que pesa sobre a homossexualidade, assim como sobre a sexualidade". ${ }^{17}$ Dialogamos com as mais diversas áreas. Não raras vezes nos confrontamos com o discurso teológico e a prática eclesiástica a esse respeito. A psicanálise também aparece aqui revelando o ocultamento forçado da sexualidade imposto pela sociedade e denominado "pecado" pelo cristianismo. Nos empenhamos em entender como as instituições religiosas lidam com a questão da homossexualidade. Assim, passamos pelo catolicismo, pelo protestantismo clássico e pelas religiões afro-brasileiras.

Ecofeminismo: tendências e debates é o tema de nosso $6^{\circ}$. número. Aqui confrontamos os ecofeminismos com suas representantes e debatedoras. Apresentamos inicialmente uma discussão da epistemologia em teologia ecofeminista. A ligação entre cultura e ecoteologia é discutida a partir das perspectivas afro-latinoamericana e asiático-coreana. No que se refere à crítica ao ecofeminismo, discutem-se problemas tais como o da associação essencialista entre mulher e natureza, e a ênfase numa ética do cuidado primordialmente feminina.

A $7^{a}$. Mandrágora se debruça sobre história, gênero e religião. Mais uma história das mulheres do que exatamente uma discussão de gênero, esse número traz contribuições importantes acerca da participação social das mulheres em diferentes períodos da história. Discutiu-se sobre a importância social das denominadas mulheres místicas, sobre a resistência de uma filósofa cínica (Hiparquia) em aceitar o "lugar comum" das mulheres de sua época, sobre a invisibilização da mulher nas abreviaturas históricas... A Inquisição volta a ser objeto de nossa análise, dessa vez para mostrar sua funcionalidade para o êxito do projeto moderno de sociedade. O período da conquista espiritual (século XVII) do Brasil vem à baila para entendermos a construção do ser homem e do ser mulher imposta aos grupos indígenas.

Por fim, Mandrágora tematiza a violência. Os artigos, em sua grande maioria, estão perpassados pela noção de violência simbólica, tendo na religião uma de suas principais aliadas. A religião, com suas heranças misóginas, seria um veículo eficaz para a naturalização e legitimação da violência de gênero. É essa a perspectiva dos escritos, que discutem a influência da religião sobre o processo de construção da identidade do homem e da mulher, sobre a culpabilização da mulher e sobre a sacralização da violência.

As Mandrágoras buscam revelar no processo de produção simbólico-religioso das instituições tradicionais produtoras de sentido, os esforços dessas instituições no sentido de secundarizar a mulher e, no processo de racionalização da atividade religiosa, negarIhe lugares de poder baseados em discursos sobre a inferioridade natural da mulher. Se o público de fiéis que engrossam as fileiras das instituições religiosas é majoritariamente feminino, como explicar que às mulheres ainda seja vetada a participação como ministras ordenadas na Igreja Católica e em um sem número de igrejas protestantes "clássicas" e pentecostais? Por que no caso de ordenação feminina cabem às mulheres as igrejas menos expressivas em termos de poder político e econômico?

Nossa militância na academia é do tipo fervorosa. Em dez anos de existência, os esforços das mulheres do NETMAL produziram 8 Mandrágoras; uma fita de vídeo sobre 
gênero, violência e religião; e criaram discípulas. Promovemos 8 seminários, todos com a participação do movimento de mulheres bem como de lideranças religiosas, 5 cursos intensivos e debatemos nossas pesquisas em nossas reuniões regulares. Por sermos uma pós-graduação que reúne estudantes de várias partes do Brasil e de outros países da América Latina (Cuba, Chile, República Dominicana, Peru, Colômbia) e da África (Angola), temos multiplicado os grupos de estudo de gênero e religião por esses lugares. Também estamos desenvolvendo uma proposta de Lato Sensu em gênero e religião. E quero lembrar que estamos em uma universidade privada e confessional o que, em muitos aspectos, limita nossa produção.

\section{Algumas questões fundamentais}

a. Crise de legitimidade

O nosso tipo de publicação vive uma constante crise de legitimidade. Mesmo na academia que tem redescoberto a religião como objeto de estudo (Associação de Cientistas Sociais da Religião no Mercosul, Associação Brasileira de História das Religiões), vivemos na tensão da necessidade de provarmos sua legitimidade. Afinal de contas, não raras vezes, estudos de religião se confundiram com teologia dogmática, com explícita apologia aos mandos e desmandos das instituições religiosas. Esse trabalho dos intelectuais orgânicos das organizações religiosas somado à suspeita moderna com relação à religião e suas mais diversas expressões, produziu uma resistência acadêmica quase impermeável ao objeto religioso. Além disso, estamos no contexto de uma universidade confessional. O dado da confessionalidade também é visto com reservas, pois poderia sugerir uma "ciência religiosa".

Em artigo sobre os estudos da religião no Brasil, Luiz Eduardo W. Wanderley referese a duas situações em que persiste uma certa aversão acadêmica aos estudos de religião:

Uma se refere à não prioridade que as temáticas religiosas recebem nos programas das agências de financiamento de pesquisas. Neste caso, faz-se necessária uma presença nesses círculos, com esclarecimentos sobre a importância do elemento religioso na sociedade em geral (...).

Outra situação refere-se ao que alguns pesquisadores e assessores de projetos definem como "análises militantes" de caráter ideológico e político (...) Se há veracidade nessa assertiva, já que determinados trabalhos apresentam um conteúdo político exacerbado, seria conveniente explicitar quais são os critérios de avaliação considerados científicos para julgar os trabalhos de temática religiosa (diferentes das outras temáticas?), numa época em que o mito da neutralidade científica parece cair por terra. E ainda, aclarar se as investigações e estudos realizados em universidades e institutos não vinculados a igrejas não seriam do mesmo modo politizados e ideologizados. ${ }^{18}$

Entretanto, não é apenas o eixo "religião" que nos empurra para a periferia da ilegitimidade. Os estudos feministas, não somente, mas, especialmente, no contexto das universidades privadas, ainda buscam uma legitimidade institucional. Raras são as universidades privadas que contemplam em sua grade curricular alguma disciplina relativa a gênero. Raros também são os grupos de pesquisa e as publicações nessa perspectiva, denunciando uma "presença acessória" do feminismo nesse universo. A transversalidade de gênero se esmaece na nebulosa indecifrável do que é "científico" e do que é ventável no contexto da universidade privada.

O dilema universidade pública $X$ universidade privada mais cedo ou mais tarde terá que ser debatido também pelas pesquisadoras feministas. Porque à pergunta por quem publica, o que publica e onde publica deve anteceder a pergunta por onde estamos 
inseridas. Isso pode viabilizar ou inviabilizar publicações; pode abrir ou fechar portas de agências de fomento à pesquisa.

b. O "faz tudo" feminista

Talvez uma herança que ainda trazemos de nosso passado recente é o complexo feminista do "faz tudo". Nós somos as que militam, as que pesquisam, as que publicam, as que revisam, as que buscam recursos, as que promovem cursos e congressos dentro e fora da universidade, as que produzem vídeo etc. Se nós questionamos a tripla jornada de trabalho, ao mesmo tempo nos impomos uma agenda que no mínimo nos vai enfartar. Nós vivemos num eterno sentimento de culpa (qualquer relação com religião não é mera coincidência) porque não damos conta plenamente de nenhum desses aspectos. Tem que haver uma divisão social do trabalho dentro do feminismo. Na verdade, ela já existe, mas nós nos negamos a aceitá-la porque tendemos a reproduzir hierarquias.

c. A ventabilidade de nossos produtos

O que produzimos ainda é consumido por um público muito específico. Gênero é considerado "problema de mulher". Em nossos cursos, seminários, grupos de pesquisa, a participação é majoritariamente feminina. Além disso, os homens que participam quase se desculpam por serem homens. Quem compra nossos produtos são mulheres, da academia ou do movimento. A diferença entre uma produção feminista e uma outra produção, reside na recepção. Quem nos consome?

No caso de uma publicação que cruza gênero e religião, nossas dificuldades são várias. Religião vende, mas religião e feminismo ou religião e estudos de gênero é heresia, portanto, não vende. É uma equação não vendável e, portanto, não publicável. O que se tem publicado a esse respeito no Brasil tende a ser majoritariamente por editoras religiosas, o que nos submete a cortes nem sempre bem-vindos e o que nos condena a algumas prateleiras empoeiradas que são visitadas por um público muito restrito. Por outro lado, as editoras não religiosas raramente têm interesse em publicar textos sobre religião.

d. Gênero e religião: um caleidoscópio de possibilidades

Muitos desafios se impõem à nossa revista. O processo de secularização aparece beneficamente ao feminismo, pois no esforço de dessacralizar as instituições religiosas, escancara suas fragilidades. Se, por um lado, temos a percepção de que, mesmo na modernidade radical, mesmo nas sociedades secularizadas, a religião ainda exerce um papel importante como mecanismo de construção da subjetividade humana, por outro esse poder deve ser relativizado, considerando-se que no contexto moderno ocidental ela perde o monopólio do significado, dividindo lugar com outros significantes como a ciência e a mídia.

De qualquer forma, o entrecruzamento de gênero e religião levanta inúmeras possibilidades de análise. No âmbito do movimento, a discussão tem se dado especialmente no que se refere à questão religião e direitos reprodutivos (Católicas pelo Direito de Decidir - CDD), uma equação tensa, pois tenso é o tema da sexualidade no contexto da religião, particularmente do cristianismo, com sua história de repressão sexual. No mais, ainda temos um desafio, porque afinal de contas a influência da confissão religiosa não se limita a questões de direitos reprodutivos. Daí a importância de discutirmos acerca da necessidade disso ser melhor contemplado na agenda do movimento.

Ainda temos investido pouco em pesquisas acerca da violência de gênero no interior do campo religioso. Os sistemas simbólico-religiosos possuem um papel ativo na cúmplice relação entre violência material e violência simbólica. $O$ discurso religioso 
misógino é apenas um dos termos que compõem a equação da violência. A forma como o homem é representado é o outro termo dessa equação. A afirmação sociocultural da masculinidade passa pelo exercício do poder do homem sobre a mulher e os filhos, e a religião tem colaborado com a reprodução dessa representação social da masculinidade.

Há que se perguntar também pelos câmbios ou continuidades do discurso religioso acerca dos papéis sociais de sexo num contexto de redefinição das identidades de gênero e da chamada "crise da masculinidade". Como a mídia religiosa tem abordado essa temática? Por que se evidencia uma certa retração de instituições religiosas católicas e protestantes clássicas em relação às conquistas femininas contemporâneas? Como o neopentecostalismo dialoga com a noção cultural de feminilidade?

As instituições religiosas se esforçam para ocultar as mudanças ocorridas em seu interior e, dessa forma, apresentarem-se como entidades permanentes, a-históricas, seguras para aqueles que a elas se agarrarem. Admitir mudanças é admitir a fragilidade de seus sistemas simbólicos. Mas os discursos religiosos são bastante cambiantes, o que nos abre um terreno fértil de possibilidades de pesquisa.

\section{Notas}

Copyright ( $\odot 2004$ by Revista Estudos Feministas.

1 Rubem ALVES, 1978, p. 112.

2 Pedro Ribeiro OLIVEIRA, 1998, p. 21.

3 Beatriz Muniz SOUZA e Luiz Mauro Sá MARTINO, 2004, p. 8.

${ }^{4}$ Cândido Procópio Ferreira CAMARGO, 1973.

${ }^{5}$ Antonio Gouvêa MENDONÇA e Beatriz Muniz SOUZA, 1998, 7.

${ }^{6}$ Clifford GEERTZ, 1989, 101-142.

7 Antônio Flavio PIERUCCI, 1997, 99-117.

${ }^{8}$ Maria das Dores Campos MACHADO em seu livro Carismáticos e Pentecostais: adesão religiosa e seus efeitos na esfera familiar (1996), analisa a importância da adesão religiosa no processo de reelaboração das identidades de gênero.

${ }^{9}$ A esse respeito, verificar PIERUCCI, 1997, p. 103.

${ }^{10}$ Sandra Duarte SOUZA, 2003, p. 6.

${ }^{11}$ A esse respeito, verificar Pierre BOURDIEU, 1999, p. 7-8.

${ }^{12}$ Sandra Duarte SOUZA, 2003, p. 7.

${ }^{13} \mathrm{~A}$ raiz da Mandrágora lembra o corpo de uma mulher. Essa raiz, desde tempos antigos, era utilizada por mulheres como narcótico, veneno, remédio, afrodisíaco e purgante. O nome é um indicador das propriedades que pode conter a revista.

${ }^{14}$ Atualmente Universidade Metodista de São Paulo - UMESP

${ }^{15}$ O NETMAL é um grupo de pesquisa sobre gênero e religião que foi organizado pelas mestrandas e doutorandas da pós-graduação em Ciências da Religião da Universidade Metodista de São Paulo - UMESP. As alunas pertencem a diferentes áreas de concentração: ciências sociais e religião; teologia e história; literatura e sociedade do mundo bíblico; práxis religiosa e sociedade.

${ }^{16} \mathrm{~A}$ esse respeito, consultar o Regimento Interno do Núcleo de Estudos Teológicos da Mulher na América Latina - NETMAL.

${ }^{17}$ Maria José Rosado NUNES, 1999, p. 5.

${ }^{18}$ Luiz Eduardo WANDERLEY, 1998, p. 28-29.

\section{Referências}

ALVES, Rubem. "A volta do sagrado: os caminhos da sociologia da religião no Brasil". Religião e Sociedade. Ed. Civilização Brasileira, 1978. p. 109-141.

BOURDIEU, Pierre. A Dominação Masculina. Rio de Janeiro: Bertrand Brasil, 1999.

CAMARGO, Cândido Procópio Ferreira. Católicos, Protestantes, Espíritas. Petrópolis: Vozes, 1973. 
GEERTZ, Clifford. A Interpretação das Culturas. Rio de Janeiro: LTC, 1989.

MACHADO. Maria da Dores Campos. Carismáticos e Pentecostais: adesão religiosa e seus efeitos na esfera familiar. Campinas: ANPOCS/Autores Associados, 1996.

MENDONÇA, Antonio Gouvêa; SOUZA, Beatriz M. "Apresentação". In: SOUZA, Beatriz M.; GOUVEIA, Eliana H.; JARDILINO, José R. (Orgs.). Sociologia da Religião no Brasil. Revisitando metodologias, classificações e técnicas de pesquisa. São Paulo: PUC/UMESP, 1998. p. 7-9.

NUNES, Maria José Rosado."Apresentação". In: Mandrágora, São Bernardo do Campo: UMESP, v.5, p. 5, 1999.

OLIVEIRA, Pedro Ribeiro. "Estudos da Religião no Brasil: um dilema entre academia e instituições religiosas". In: SOUZA, Beatriz. M.; GOUVEIA, Eliana. H. e JARDILINO, José R. (Orgs.). Sociologia da Religião no Brasil. Revisitando metodologias, classificações e técnicas de pesquisa. São Paulo: PUC/UMESP, 1998. p. 13-24.

PIERUCCI, Antônio Flavio. "Reencantamento e Dessecularização". Novos Estudos. CEBRAP, n. 49, p. 99-117, nov. 1997.

SOUZA, Beatriz Muniz; MARTINO, Luís Mauro Sá. "A compreensão de um paradoxo". In: SOUZA, Beatriz M.; GOUVEIA, Eliana H. e JARDILINO, José R. (Orgs.). Sociologia da Religião e Mudança Social: católicos, protestantes e novos movimentos religiosos no Brasil. São Paulo: Paulus, 2004. p. 7-10.

SOUZA, Sandra Duarte de. "Entrecruzamento gênero e religião: um desafio para os estudos feministas". Mandrágora, São Bernardo do Campo: UMESP, v. 7/8, p. 6-8, 2003.

WANDERLEY, Luiz Eduardo W. "Estudos da Religião no Brasil: buscando o equilíbrio entre adaptação e criatividade." In: SOUZA, Beatriz M.; GOUVEIA, Eliana H. e JARDILINO, José R. (Orgs.). Sociologia da Religião no Brasil. Revisitando metodologias, classificações e técnicas de pesquisa. São Paulo: PUC/UMESP, 1998. p. 25-36.

\section{Revista Mandragóra:Gender and Religion in Feminist Studies}

Abstract: Gender and religion constitute a still little discussed and admited equation. In the field of feminist studies this relation is still referred to in a very timid way. The initiatives of studing this issue are very scarce specially by specific journals in the gender area. The two more expressive academic feminist journals in Brasil - Revista Estudos Feministas and Cadernos Pagu - have been an important site to discuss this theme. Another publication to be outlined in this area is Revista Mandrágora, a specific journal on feminist studies and religion.

Keywords: gender; religion; feminist publications 